\title{
Sleep Disorders Prior to Adjuvant Radiation Therapy for Gynecological Malignancies
}

\author{
DIRK RADES ${ }^{1}$, SVENJA KOPELKE ${ }^{1,2}$, TAMER SOROR ${ }^{1}$, STEVEN E. SCHILD ${ }^{3}$, \\ SOEREN TVILSTED ${ }^{4}$, TROELS W. KJAER ${ }^{5}$ and TOBIAS BARTSCHT ${ }^{2}$ \\ ${ }^{1}$ Department of Radiation Oncology, University of Lübeck, Lübeck, Germany; \\ ${ }^{2}$ Department of Hematology and Oncology, University of Lübeck, Lübeck, Germany; \\ ${ }^{3}$ Department of Radiation Oncology, Mayo Clinic, Scottsdale, AZ, U.S.A.; \\ ${ }^{4}$ Research Projects and Clinical Optimization, Zealand University Hospital, Koege, Denmark; \\ ${ }^{5}$ Neurological Department, Zealand University Hospital, Roskilde, Denmark
}

\begin{abstract}
Background/Aim: Many patients with gynecological malignancies receive postoperative radiotherapy, which can lead to fear and sleep disorders. We aimed to identify the prevalence of and risk factors for sleep disorders. Patients and Methods: Sixty-two patients assigned to radiotherapy for gynecological malignancies were retrospectively evaluated. Seventeen characteristics were analyzed for associations with pre-radiotherapy sleep disorders including age, Karnofsky performance score, Charlson comorbidity index, history of additional malignancy, family history of gynecological cancer, distress score, emotional, physical or practical problems, tumor site/stage; chemotherapy, treatment volume, brachytherapy, and the COVID-19 pandemic. Results: The prevalence of preradiotherapy sleep disorders was $46.8 \%$. Sleep disorders were significantly associated with Charlson comorbidity index $\geq 3$ $(p=0.012)$, greater number of physical problems $(p<0.0001)$, and advanced primary tumor stage $(p=0.005)$. A trend was found for greater number of emotional problems $(p=0.075)$. Conclusion: Pre-radiotherapy sleep disorders are common in patients with gynecological malignancies, particularly in those with specific risk factors. Patients should be offered early psychological support.
\end{abstract}

After breast cancer, gynecological malignancies represent the second most common group of female cancers (1). Many of

This article is freely accessible online.

Correspondence to: Prof. Dirk Rades, MD, Department of Radiation Oncology, University of Lübeck, Ratzeburger Allee 160, 23562 Lübeck, Germany. Tel: +49 45150045401, Fax: +49 45150045404, e-mail: dirk.rades@uksh.de

Key Words: Gynecological cancer, adjuvant radiotherapy, sleep disorders, prevalence, risk factors. these patients receive local or locoregional radiotherapy, either with external beam radiotherapy (EBRT), brachytherapy or both. Anticipation of a course of radiotherapy can lead to fear and nervousness about the high-tech machinery, exposure to radiation, and potential treatment-related adverse events $(2,3)$. One potential consequence of these concerns is the occurrence of sleep disorders.

In the studies of Savard et al., patients with gynecological malignancies had a high prevalence of insomnia compared to many other primary tumor types $(4,5)$. Moreover, in a study of patients irradiated for breast or prostate cancer, sleep disorders occurred mainly before or during the initial phase of treatment (6). Very limited data are available regarding the prevalence of pre-treatment sleep disorders and corresponding risk factors in patients receiving postoperative radiotherapy for gynecological cancers. Therefore, the present study aimed to identify risk factors for occurrence of pre-radiotherapy sleep disorders in these patients. These risk factors can contribute to the identification of patients who need early psychological support.

\section{Patients and Methods}

Sixty-two patients assigned to postoperative radiation therapy for a gynecological malignancy who completed the evaluation of distress using the National Comprehensive Cancer Network Distress Thermometer $(7,8)$ were included in this retrospective study, which received approval from the ethics committee of the University of Lübeck (reference number: 21-284). Thirty-three patients had uterine cancer (endometrial carcinoma), 26 cervix cancer, two vulvar cancer, and one patient vaginal cancer. Thirty-five patients received EBRT alone to the region of the primary tumor and the loco-regional lymph nodes with total doses ranging between 45.0 Gy and $64.8 \mathrm{~Gy}$ (median dose=50.4 Gy) and a dose per fraction of $1.8 \mathrm{~Gy}$. Four patients were treated with 50.4 Gy of EBRT plus brachytherapy $(3 \times 7 \mathrm{~Gy}$, one fraction per week) as a boost. Twentythree patients received brachytherapy $(4 \times 5 \mathrm{~Gy}$, one fraction per week) alone, mainly for T1-tumors. Five patients had received 
chemotherapy only prior to the start of radiotherapy, four of these patients with carboplatin/paclitaxel for endometrial carcinoma and one patient with cisplatin/etoposide for small cell carcinoma of the uterine cervix. One patient received carboplatin/paclitaxel both before and during the course of radiotherapy. In additional 24 patients, concurrent chemotherapy was administered only during the radiotherapy course. Twenty-three patients received weekly cisplatin or carboplatin for cancer of the cervix $(n=22)$ or the vagina $(n=1)$, and one patient two cycles of mitomycin C (days 1 and 29 of the radiotherapy course). In two additional patients, weekly cisplatin was planned but not given due to patient's refusal or co-morbidity.

Sleep disorders (no vs. yes) were assessed prior to radiotherapy. A total of 17 patient and tumor characteristics were evaluated for associations with the occurrence of sleep disorders. These characteristics included age ( $\leq 63$ vs. $\geq 64$ years, median=63.5 years); Karnofsky performance score (60-80 vs. 90-100); Charlson comorbidity index (2 $v s . \geq 3$, median=2); history of previous or concurrent malignancy (no $v s$. yes); family history of gynecological cancer (no $v s$. yes); distress score (0-5 vs. 6-10; median=5) according to the National Comprehensive Cancer Network Distress Thermometer $(7,8)$; number of emotional (0$1 v s . \geq 2$, median=1.5), physical $(0-3 v s . \geq 4$, median=4) or practical ( 0 $v s . \geq 1$, median $=0$ ) problems according to the Distress Thermometer; tumor site (cervix $v s$. uterus $v s$. vagina/vulva); primary tumor stage (T12 vs. T3-4); nodal stage ( $\mathrm{N} 0$ vs. $\mathrm{N}+$ ); distant metastasis (no=M0 vs. yes=M1); chemotherapy prior to or during the radiotherapy course (no $v s$. yes); treatment volume of radiotherapy (without $v s$. with locoregional lymph nodes); brachytherapy (no vs. yes); and time-related reference to the COVID-19 pandemic (before $v s$. during the pandemic). The distributions of these characteristics are summarized in Table I.

For the statistical analyses regarding associations between the 17 characteristics and pre-radiotherapy sleep disorders, the chi-square test and the Fisher's exact test (in case of $\mathrm{n}<5$ ) were used. $p$-Values $<0.05$ were considered to indicate significance and $p$-values $<0.08$ to indicate a trend for an association with sleep disorders.

\section{Results}

The prevalence of pre-radiotherapy sleep disorders in the entire cohort was $46.8 \%$ ( 29 of 62 patients). Sleep disorders were significantly associated with a Charlson comorbidity index of $\geq 3$ ( $p=0.012)$, greater number of physical problems $(p<0.0001)$, and more advanced primary tumor stage (T3-4, $p=0.005)$. Moreover, a trend was observed for a greater number of emotional problems $(p=0.075)$ (Table II). The COVID-19 pandemic had no significant impact on the occurrence of pre-radiotherapy sleep disorders $(p=0.33)$.

\section{Discussion}

Many patients with gynecological cancer receive radiotherapy and/or chemotherapy, which can cause sleep disorders due to fear and nervousness (9-11). The prevalence of sleep disorders in patients with gynecological malignances reported in the literature ranged between $25 \%$ and $68 \%(4,5,12-14)$. In two previous studies, prevalence of insomnia in patients with gynecological malignancies ranged from 33 to $68 \%$ and from 49 to $68 \%$, respectively, and was higher than in most patients with other primary tumors $(4,5)$. Moreover, in a study of 330 cancer patients, the prevalence of sleep disturbances was $43.8 \%$ in patients with cervix cancer, which was the second highest cancer-specific prevalence following lung cancer (prevalence $=45.2 \%$ ) (14). However, no study has been reported that focused particularly on sleep disorders prior to a course of postoperative radiotherapy for gynecological cancer and the corresponding risk factors.

This study was performed to fill this gap, since the determination of such risk factors would help identify patients requiring early psychological support. The occurrence of preradiotherapy sleep disorders was significantly associated with Charlson comorbidity index, number of physical problems, and primary tumor stage. In addition, the number of emotional problems showed a trend. These findings agree with the results of previous studies that investigated sleep problems in patients wirh gynecological cancers but did not focus on preradiotherapy sleep disorders. Aquil et al. performed a crosssectional study of 100 patients with gynecological cancer who underwent radical surgery and found significant correlations between sleep disorders and emotional problems such as anxiety and depression (15). In the study of Sandadi et al., 86 patients with ovarian, fallopian tube or primary peritoneal cancer during the last 5 years completed a questionnaire (16). Thirty-one patients (36\%) had current disease, of whom $81 \%$ received chemotherapy. Sleep disorders were significantly associated with physical ( $p<0.001)$, functional $(p<0.001)$, and emotional $(p<0.001)$ problems. Similar to our study, no significant associations were found between sleep disorders and age or previous chemotherapy. Associations between sleep disorders and physical and emotional problems were also found in two previous studies investigating pre-radiotherapy sleep disorders in breast cancer patients $(17,18)$. Moreover, in one of these studies, a trend was observed for an association between sleep disorders and a higher Charlson comorbidity index (17). According to our knowledge, associations between a more advanced primary tumor stage and pre-treatment sleep disorders were not previously reported for patients irradiated for gynecological malignancies. However, the fact that more advanced tumors are associated with worse prognoses likely had an effect on emotional problems and distress and, subsequently, on the occurrence of sleep disorders. Despite some consistency with the results of previous reports, the limitations of the present study, in particular its retrospective design and the comparably small patient number should be kept in mind.

In conclusion, pre-radiotherapy sleep disorders are common in patients with gynecological malignancies, particularly in case of risk factors such as Charlson comorbidity index $\geq 3$, advanced primary tumor stage, or higher numbers of physical and emotional problems. Particularly patients with one or more of these risk factors should be offered early psychological support. 
Table I. Characteristics investigated for sleep disorders prior to radiotherapy.

\begin{tabular}{|c|c|}
\hline Characteristic & $\begin{array}{c}\text { Frequency, } \\
\text { n }(\%)\end{array}$ \\
\hline \multicolumn{2}{|l|}{ Age } \\
\hline$\leq 63$ Years & $31(50)$ \\
\hline$\geq 64$ Years & $31(50)$ \\
\hline \multicolumn{2}{|c|}{ Karnofsky performance score } \\
\hline $60-80$ & $20(32)$ \\
\hline $90-100$ & $42(68)$ \\
\hline \multicolumn{2}{|c|}{ Charlson comorbidity index } \\
\hline 2 & $34(55)$ \\
\hline$\geq 3$ & $28(45)$ \\
\hline \multicolumn{2}{|c|}{ History of another malignancy } \\
\hline No & $50(81)$ \\
\hline Yes & $12(19)$ \\
\hline \multicolumn{2}{|c|}{ Family history of gynecological cancer } \\
\hline No & $51(82)$ \\
\hline Yes & $7(11)$ \\
\hline Unknown & $4(6)$ \\
\hline \multicolumn{2}{|l|}{ Distress score } \\
\hline $0-5$ & $40(65)$ \\
\hline $6-10$ & $22(35)$ \\
\hline \multicolumn{2}{|c|}{ Number of emotional problems } \\
\hline $0-1$ & $31(50)$ \\
\hline$\geq 2$ & $31(50)$ \\
\hline \multicolumn{2}{|c|}{ Number of physical problems } \\
\hline $0-3$ & $27(44)$ \\
\hline$\geq 4$ & $35(56)$ \\
\hline \multicolumn{2}{|c|}{ Number of practical problems } \\
\hline 0 & $44(71)$ \\
\hline$\geq 1$ & $18(29)$ \\
\hline \multicolumn{2}{|l|}{ Tumor site } \\
\hline Cervix & $26(42)$ \\
\hline Uterus & $33(53)$ \\
\hline Vagina/Vulva & $3(5)$ \\
\hline \multicolumn{2}{|c|}{ Primary tumor stage } \\
\hline $\mathrm{T} 1-2$ & $45(73)$ \\
\hline $\mathrm{T} 3-4$ & $17(27)$ \\
\hline \multicolumn{2}{|l|}{ Nodal stage } \\
\hline No & $41(66)$ \\
\hline $\mathrm{N}+$ & $21(34)$ \\
\hline \multicolumn{2}{|c|}{ Distant metastasis } \\
\hline M0 & $55(89)$ \\
\hline M1 & $7(11)$ \\
\hline \multicolumn{2}{|c|}{ Chemotherapy prior to or during $\mathrm{RT}$} \\
\hline No & $31(50)$ \\
\hline Yes & $31(50)$ \\
\hline \multicolumn{2}{|c|}{ Treatment volume of RT } \\
\hline Without LN & $23(37)$ \\
\hline With LN & $39(63)$ \\
\hline \multicolumn{2}{|l|}{ Brachytherapy } \\
\hline No & $17(27)$ \\
\hline Yes & $45(73)$ \\
\hline \multicolumn{2}{|c|}{ COVID-19 pandemic } \\
\hline Before & $34(55)$ \\
\hline During & $28(45)$ \\
\hline
\end{tabular}

LN: Lymph nodes; RT: radiotherapy; COVID-19: Coronavirus Disease 2019.
Table II. Associations of characteristics with sleep disorders prior to radiotherapy.

\begin{tabular}{|c|c|c|c|}
\hline \multirow[b]{2}{*}{ Characteristic } & \multicolumn{2}{|c|}{ Sleep disorders, $\mathrm{n}(\%)$} & \multirow[b]{2}{*}{$p$-Value } \\
\hline & Yes $(n=29)$ & No $(n=33)$ & \\
\hline \multicolumn{4}{|l|}{ Age } \\
\hline$\leq 63$ Years & $16(55)$ & $15(45)$ & 0.45 \\
\hline$\geq 64$ Years & $13(45)$ & $18(55)$ & \\
\hline \multicolumn{4}{|c|}{ Karnofsky performance score } \\
\hline $60-80$ & $12(41)$ & $8(24)$ & 0.15 \\
\hline $90-100$ & $17(59)$ & $25(76)$ & \\
\hline \multicolumn{4}{|c|}{ Charlson comorbidity index } \\
\hline 2 & $11(38)$ & $23(70)$ & 0.012 \\
\hline$\geq 3$ & $18(62)$ & $10(30)$ & \\
\hline \multicolumn{4}{|c|}{ History of another malignancy } \\
\hline No & $22(76)$ & $28(85)$ & 0.37 \\
\hline Yes & $7(24)$ & $5(15)$ & \\
\hline \multicolumn{4}{|c|}{$\begin{array}{l}\text { Family history of gynecological } \\
\text { cancer }\end{array}$} \\
\hline No & $22(81)$ & $29(94)$ & 0.23 \\
\hline Yes & $5(19)$ & $2(6)$ & \\
\hline \multicolumn{4}{|l|}{ Distress-score } \\
\hline $0-5$ & $17(59)$ & $23(70)$ & 0.36 \\
\hline $6-10$ & $12(41)$ & $10(30)$ & \\
\hline \multicolumn{4}{|c|}{ Number of emotional problems } \\
\hline $0-1$ & $11(38)$ & $20(61)$ & 0.075 \\
\hline$\geq 2$ & $18(62)$ & $13(39)$ & \\
\hline \multicolumn{4}{|c|}{ Number of physical problems } \\
\hline $0-3$ & $4(14)$ & $23(70)$ & $<0.0001$ \\
\hline$\geq 4$ & $25(86)$ & $10(30)$ & \\
\hline \multicolumn{4}{|c|}{ Number of practical problems } \\
\hline 0 & $18(62)$ & $26(79)$ & 0.15 \\
\hline$\geq 1$ & $11(38)$ & $7(21)$ & \\
\hline \multicolumn{4}{|l|}{ Tumor site } \\
\hline Cervix & $13(45)$ & $13(39)$ & 0.84 \\
\hline Uterus & $15(52)$ & $18(55)$ & \\
\hline Vagina/Vulva & $1(3)$ & $2(6)$ & \\
\hline \multicolumn{4}{|c|}{ Primary tumor stage } \\
\hline $\mathrm{T} 1-2$ & $16(55)$ & $29(88)$ & 0.005 \\
\hline $\mathrm{T} 3-4$ & $13(45)$ & $4(12)$ & \\
\hline \multicolumn{4}{|l|}{ Nodal stage } \\
\hline No & $20(69)$ & $21(64)$ & 0.66 \\
\hline $\mathrm{N}+$ & $9(31)$ & $12(36)$ & \\
\hline \multicolumn{4}{|c|}{ Distant metastasis } \\
\hline M0 & $24(83)$ & $31(94)$ & 0.24 \\
\hline M1 & $5(17)$ & $2(6)$ & \\
\hline \multicolumn{4}{|c|}{$\begin{array}{l}\text { Chemotherapy prior to } \\
\text { or during RT }\end{array}$} \\
\hline No & $13(45)$ & $18(55)$ & 0.45 \\
\hline Yes & $16(55)$ & $15(45)$ & \\
\hline \multicolumn{4}{|c|}{ Treatment volume of RT } \\
\hline Without LN & $12(41)$ & $11(33)$ & 0.51 \\
\hline With LN & $17(59)$ & $22(67)$ & \\
\hline \multicolumn{4}{|l|}{ Brachytherapy } \\
\hline No & $9(31)$ & $8(24)$ & 0.55 \\
\hline Yes & $20(69)$ & $25(76)$ & \\
\hline \multicolumn{4}{|c|}{ COVID-19 pandemic } \\
\hline Before & $14(48)$ & $20(61)$ & 0.33 \\
\hline During & $15(52)$ & $13(39)$ & \\
\hline
\end{tabular}

LN: Lymph nodes; RT: radiotherapy; COVID-19: Coronavirus Disease 2019. Statistically significant $p$-values are shown in bold. 


\section{Conflicts of Interest}

The Authors have no conflicts of interest related to this study.

\section{Authors' Contributions}

D.R., S.K., T.S., S.T., T.W.K and T.B. participated in the design of the study. D.R. and S.K. provided the data. D.R. and S.E.S. performed the analyses. D.R. and S.E.S. drafted the article, which was reviewed and finally approved by all Authors.

\section{Acknowledgements}

As part of the project NorDigHealth, this study was funded by the European Regional Development Fund through the Interreg Deutschland-Danmark program.

\section{References}

1 Siegel RL, Miller KD, Fuchs HE and Jemal A: Cancer statistics, 2021. CA Cancer J Clin 71(1): 7-33, 2021. PMID: 33433946. DOI: $10.3322 /$ caac. 21654

2 Koutras A, Peteinaris A, Davakis S, Kalinterakis G, Tsilikis I, Garmpis N, Zotos PA, Chionis A, Schizas D, Karavokyros I, Thomakos N, Kontomanolis E and Syllaios A: Surgical versus conservative treatment for endometrial cancer in women of reproductive age: incidence of urinary tract symptoms. Anticancer Res 40(6): 3065-3069, 2020. PMID: 32487600. DOI: 10.21873 /anticanres. 14287

3 Guliyeva G, Huayllani MT, Avila FR, Boczar D, Lu X and Forte AJ: Younger age as a risk factor for gynecologic cancer-related lymphedema: a systematic review. Anticancer Res 40(12): 66096612, 2020. PMID: 33288555. DOI: 10.21873/anticanres.14685

4 Savard J, Ivers H, Villa J, Caplette-Gingras A and Morin CM: Natural course of insomnia comorbid with cancer: an 18-month longitudinal study. J Clin Oncol 29(26): 3580-3586, 2011. PMID: 21825267. DOI: 10.1200/JCO.2010.33.2247

5 Savard J, Villa J, Ivers H, Simard S and Morin CM: Prevalence, natural course, and risk factors of insomnia comorbid with cancer over a 2-month period. J Clin Oncol 27(31): 5233-5239, 2009. PMID: 19738124. DOI: 10.1200/JCO.2008.21.6333

6 Thomas KS, Bower J, Hoyt MA and Sepah S: Disrupted sleep in breast and prostate cancer patients undergoing radiation therapy: the role of coping processes. Psychooncology 19(7): 767-776, 2010. PMID: 19885853. DOI: 10.1002/pon.1639

7 Holland JC, Andersen B, Breitbart WS, Buchmann LO, Compas B, Deshields TL, Dudley MM, Fleishman S, Fulcher CD, Greenberg DB, Greiner CB, Handzo GF, Hoofring L, Hoover C, Jacobsen PB, Kvale E, Levy MH, Loscalzo MJ, McAllister-Black R, Mechanic KY, Palesh O, Pazar JP, Riba MB, Roper K, Valentine AD, Wagner LI, Zevon MA, McMillian NR and Freedman-Cass DA: Distress management. J Natl Compr Canc Netw 11(2): 190209, 2013. PMID: 23411386. DOI: 10.6004/jncen.2013.0027

8 Mehnert A, MÃ¹/4ller D, Lehmann C and Koch U: Die deutsche Version des NCCN Distress-Thermometers. Zeitschrift für Psychiatrie, Psychologie und Psychotherapie 54(3): 213-223, 2021. DOI: $10.1024 / 1661-4747.54 .3 .213$
9 Gadducci A and Cosio S: Neoadjuvant chemotherapy in locally advanced cervical cancer: review of the literature and perspectives of clinical research. Anticancer Res 40(9): 48194828, 2020. PMID: 32878770. DOI: 10.21873/anticanres.14485

10 Shimoji Y, Nagai Y, Toita T, Ariga T, Heianna J, Nakasone T, Taira Y, Arakaki Y, Nakamoto T, Ooyama T, Kudaka W, Kaneshima I, Nishihira K, Mekaru K and Aoki Y: A Phase II study of neoadjuvant chemotherapy followed by extended field concurrent chemoradiotherapy for para-aortic lymph node positive cervical cancer. Anticancer Res 40(6): 3565-3570, 2020. PMID: 32487659. DOI: 10.21873/anticanres.14346

11 Gadducci A, Pistolesi S, Cosio S and Naccarato AG: Is perineural invasion a novel prognostic factor useful to tailor adjuvant treatment in patients treated with primary surgery for cervical and vulvar carcinoma? Anticancer Res 40(6): 30313037, 2020. PMID: 32487596. DOI: 10.21873/anticanres.14283

12 Tuyan İlhan T, Uçar MG, Gül A, Saymaz İlhan T, Yavaş G and Çelik Ç: Sleep quality of endometrial cancer survivors and the effect of treatments. Turk J Obstet Gynecol 14(4): 243-248, 2017. PMID: 29379668. DOI: $10.4274 /$ tjod.59265

13 Tian J, Chen GL and Zhang HR: Sleep status of cervical cancer patients and predictors of poor sleep quality during adjuvant therapy. Support Care Cancer 23(5): 1401-1408, 2015. PMID: 25370891. DOI: 10.1007/s00520-014-2493-8

14 Wang J, Zhou BY, Lian CL, Zhou P, Lin HJ and Wu SG: Evaluation of subjective sleep disturbances in cancer patients: a cross-sectional study in a radiotherapy department. Front Psychiatry 12: 648896, 2021. PMID: 33868056. DOI: 10.3389/fpsyt.2021.648896

15 Aquil A, El Kherchi O, El Azmaoui N, Mouallif M, Guerroumi M, Chokri A, Jayakumar AR, Benider A and Elgot A: Body image dissatisfaction and lower self-esteem as major predictors of poor sleep quality in gynecological cancer patients after surgery: cross-sectional study. BMC Womens Health 21(1): 229, 2021. PMID: 34082733. DOI: 10.1186/s12905-021-01375-5

16 Sandadi S, Frasure HE, Broderick MJ, Waggoner SE, Miller JA and von Gruenigen VE: The effect of sleep disturbance on quality of life in women with ovarian cancer. Gynecol Oncol 123(2): 351355, 2011. PMID: 21855973. DOI: 10.1016/j.ygyno.2011.07.028

17 Rades D, Narvaez CA, Dziggel L, Tvilsted S and Kjaer TW: Sleep disorders in patients with breast cancer prior to a course of radiotherapy - prevalence and risk factors. Anticancer Res 41(5): 2489-2494, 2021. PMID: 33952476. DOI: $10.21873 /$ anticanres. 15026

18 Rades D, Narvaez CA, Schild SE, Tvilsted S and Kjaer TW: Sleep disorders before and during the COVID-19 pandemic in patients assigned to adjuvant radiotherapy for breast cancer. In Vivo 35(4): 2253-2260, 2021. PMID: 34182504. DOI: 10.21873/invivo.12498 